Notes has now ceased. Their place is being taken by a new series, New Zealand Forestry Research Notes, published by the Government Printer, Wellington, which will report research carried out in New Zealand in any field of forestry by all types of worker-public, private, university, etc. The annual report of the Forest Research Institute, Whakarewarewa, will now be issued independently of any research series.

Pinus radiata forms a considerable proportion of the coniferous species constituting the new New Zea. land forests and has been the subject of a great deal of research work. No. 1 of Neu Zealand Forestry Research Notes (pp. 72; 1955) treats of combined taper and volume tables for $P$. radiata for 1952 in unthinned stands in the Conservancies of Auckland, Nelson and Canterbury and in thinned stands in the fourth Conservancy of Southland. Technical Paper No. 4 of the Forest Research Institute (pp. 48) deals with some comparative tests with wood preservatives and covers work still incomplete for $P$. radiata that has been carried out in all four Conservancies.

\section{Soil, Vegetation and Land-use Surveys in the Gold Coast}

The first of a series of memoirs to be published by the Gold Coast Department of Soil and Land-Use Survey, Kumasi, is a report, with detailed recommendations, on a "Detailed Soil Survey of the Kpong Pilot Irrigation Area" by H. Brammer (pp. 102+9 maps. Accra : Govt. Printer; London: Crown Agents ; 1955; 10s.). It gives a survey of the irrigation research station on the Accra plains, where experiments are now being carried out to establish, among other things, the most suitable means for irrigating approximately three hundred square miles of tropical black clays. Besides reports on detailed surveys of development areas, this series is to include comprehensive reports and monographs on particular aspects of the systematic soil, vegetation and land-use survoy of the country as a whole.

\section{Chemistry Institute at Bogor, Indonesia}

Under the Colombo Plan, Mr. H. J. Wood, chemist in charge of the food and drugs section of the Dominion Laboratory, Department of Scientific and Industrial Research, New Zealand, has been loaned for twelve months to the Government of Indonesia and will teach now methods of chemical analysis to the staff of the Chemistry Institute at Bogor. The Institute, which is in the grounds of the well-known botanical gardens at Bogor, covers a wide field of investigation; but its chief interests are the developing of the natural food resources of Indonesia and methods of control for quality-both processing and analytical control. There is a staff of two hundred; but only three of them are qualified chemists. Bogor contains a small European population, and besides the Chemistry Institute there are an agricultural institute and an American plant for the rubber industry.

\section{Measurement of Rate of Dewfall}

A PAPER by Dr. G. Hoffmann, published in Berichte des Deutschen Wetterdienstes (3, No. $18 ; 1955)$, discusses the thermodynamics of and meteorological conditions for dew formation, and then goes on to describe a novel instrument, invented by Dr. Hoffmann, for measuring directly the rate of dewfall based upon the release of latent heat to the body upon which the dew forms. The rate, of the order of $0.02 \mathrm{~mm}$./hr., needs a very sensitive apparatus for its measurement. The apparatus consists of a series of separate radial sectors, the temperature differences between which can be measured thermoelectrically. One sector is unheated so that dew forms upon it, an adjacent one is heated at a certain rate $H$ and a third sector on the far side of the second from the first at a rate $2 \mathrm{H}$. The temperature difference between adjacent segments is, in the steady state, proportional to the difference in the rates at which they are being heated, the constant of proportionality depending on wind and temperature. The arrangement gives the rate of dewfall as directly proportional to the ratio of two of the temperature differences. By using a fourth sector of different type of surface, the radiation balance can be measured and the heat conducted from the interior of the apparatus measured from temperature differences to obtain all the terms in the energy balance. A number of curves of rate of dewfall given by the instrument are reproduced, showing rates of dew formation and in some cases subsequent evaporation, amount of dew deduced from the sum of the rates, the radiation balance and the meteorological conditions. The correspondence between the records of dew formation and evaporation and radiation balance is good, but the computed dewfall showed sometimes marked differences from the total dewfall measured by a nearby Leick dewplate which gives an amount from the volume of dew on the plate, the thermoelectric apparatus apparently giving totals about half those given by the dow-plate. Further improvements of the apparatus to provide an accurate picture of the nocturnal heat balance of the ground surface are envisaged.

International Association for the Exchange of Students for Technical Experience

THe continuing success of the scheme launched by the International Association for the Exchange of Students for Technical Experience in 1948 indicates that industry in many countries now appreciates the facilities offered for the general broadening of the outlook of the students taking part in the scheme by means of travel abroad, living and working with the people of other nations and, at the same time, obtaining some useful experience in the industry of another country. In 1955 the number of students taking part in the scheme was 5,153-an increase of 886 over 1954. More interesting is that, while, in 1948, 413 industries were participating in the scheme, in 1955 the number had risen to 2,314 . Difficulties about establishing a central committce for the Association in the United States have now been overcome and in September 1955 the American Society of Engineering Education gave an official mandate to the Institute of Education for its sponsorship of the Association in the United States. India and Turkey joined the Association as associate members in January 1955, and it is anticipated that South Africa will join shortly.

\section{Institute of Personnel Management}

AN examination scheme for new entrants has been launched by the Institute of Personnel Management. The aim of the scheme is to widen the field of recruitment while ensuring that those recruited are suitably qualified for membership. The Institute will not organize any course of study; but students will be free to prepare for the examination by attending evening classes or by private reading. The choice of subjects is wide, so that people with different experi- 